\title{
Clinical Characteristics and Outcomes of Patients with Lung Cancer and Venous Thromboembolism
}

\author{
Pedro Ruiz-Artacho ${ }^{1}$ Javier Trujillo-Santos ${ }^{2}$ Luciano López-Jiménez ${ }^{3}$ Carme Font ${ }^{4}$ \\ María del Carmen Díaz-Pedroche ${ }^{5}$ Juan Francisco Sánchez Muñoz-Torrero ${ }^{6}$ Maria Luisa Peris ${ }^{7}$ \\ Andris Skride ${ }^{8}$ Ana Maestre ${ }^{9}$ Manuel Monreal ${ }^{10}$ and the RIETE Investigators*
}

${ }^{1}$ Department of Emergency, Hospital Clínico San Carlos, Madrid, Spain

2 Department of Internal Medicine, Hospital General Universitario Santa Lucía, Murcia, Spain

${ }^{3}$ Department of Internal Medicine, Hospital Universitario Reina Sofía, Córdoba, Spain

${ }^{4}$ Department of Medical Oncology, Hospital Clínic, Barcelona, Spain

${ }^{5}$ Department of Internal Medicine, Hospital Universitario 12 de Octubre, Madrid, Spain

${ }^{6}$ Department of Internal Medicine, Hospital San Pedro de Alcántara, Cáceres, Spain

7 Department of Internal Medicine, Consorcio Hospitalario Provincial de Castellón, CEU Cardenal Herrera University, Castellón, Spain

${ }^{8}$ Department of Cardiology, Pauls Stradins Clinical University Hospital, Riga, Latvia

${ }^{9}$ Department of Internal Medicine, Hospital Universitario de Vinalopó, Elche, Alicante, Spain

10 Department of Internal Medicine, Hospital Germans Trias i Pujol, Universidad Autónoma de Barcelona, Badalona, Barcelona, Spain
Address for correspondence Manuel Monreal, MD, PhD, Department of Internal Medicine, Hospital Universitari Germans Trias i Pujol, 08916 Badalona, Barcelona, Spain (e-mail: mmonreal.germanstrias@gencato.cat).

TH Open 2018;2:e210-e217.

\author{
Abstract

\section{Keywords} \\ - venous thrombosis \\ - pulmonary embolism \\ - recurrences \\ - bleeding \\ - anticoagulant \\ therapy \\ - lung cancer
}

Background The natural history of patients with lung cancer and venous thromboembolism (VTE) has not been consistently evaluated.

Methods We used the RIETE (Registro Informatizado Enfermedad TromboEmbólica) database to assess the clinical characteristics, time course, and outcomes during anticoagulation of lung cancer patients with acute, symptomatic VTE.

Results As of May 2017, a total of 1,725 patients were recruited: 1,208 (70\%) presented with pulmonary embolism (PE) and 517 with deep vein thrombosis (DVT). Overall, 865 patients (50\%) were diagnosed with cancer $<3$ months before, $1,270(74 \%)$ had metastases, and 1,250 (72\%) had no additional risk factors for VTE. During anticoagulation (median, 93 days), 166 patients had symptomatic VTE recurrences (recurrent DVT: 86, PE: 80), 63 had major bleeding (intracranial 11), and 870 died. The recurrence rate was twofold higher than the major bleeding rate during the first month, and over threefold higher beyond the first month. Fifty-seven patients died of PE and 15 died of bleeding. Most fatal PEs (84\%) and most fatal bleeds (67\%) occurred within the first month of therapy. Nine patients with fatal PE $(16 \%)$ died within the first 24 hours. Of 72 patients dying of PE or bleeding, $15(21 \%)$ had no metastases and $29(40 \%)$ had the VTE shortly after surgery or immobility.

* A full list of the RIETE investigators is given in Appendix A.

received

March 7, 2018

accepted

April 23, 2018
DOI https://doi.org/

$10.1055 / \mathrm{s}-0038-1656542$. ISSN 2512-9465. (c) 2018 Georg Thieme Verlag KG Stuttgart · New York
License terms

(c) (1) 
Conclusion Active surveillance on early signs and/or symptoms of VTE in patients with recently diagnosed lung cancer and prescription of prophylaxis in those undergoing surgery or during periods of immobilization might likely help prevent VTE better, detect it earlier, and treat it more efficiently.

\section{Introduction}

Lung cancer is the most common malignancy, and a leading cause of death. ${ }^{1}$ Patients with lung cancer are at increased risk for venous thromboembolism (VTE), ${ }^{2-6}$ and VTE appearing in patients with cancer carries an increased risk for early mortality. ${ }^{2,7}$ Unfortunately, however, there is scarce information in the literature on the clinical presentation, timecourse, and clinical outcomes of lung cancer patients developing VTE in real-life practice. A better knowledge of the burden of VTE in lung cancer patients, linked to adequate dissemination of the data, could likely help improve the awareness of attending doctors, nurses, and patients. A better understanding of at-risk patients and time course of VTE could likely help design better prevention strategies and detect VTE earlier. Finally, a better information on the natural history of VTE during the course of anticoagulant therapy could likely help design better therapeutic strategies (drugs, doses, duration) for this subgroup of patients with cancer.

The RIETE (Registro Informatizado Enfermedad Trombo Embólica) registry is an ongoing, multicenter, international, observational registry of consecutive patients with objectively confirmed acute VTE (ClinicalTrials.gov identifier: NCT02832245). Data from this registry have been used to evaluate outcomes after acute VTE, such as the frequency of recurrent VTE, bleeding and mortality, and risk factors for these outcomes. ${ }^{8-12}$ The aim of the current study was to assess the clinical characteristics, time course of VTE, and clinical outcomes during anticoagulant therapy in all patients with lung cancer presenting with symptomatic VTE.

\section{Methods}

This study is an analysis of prospectively collected data in the RIETE registry, from 209 hospitals in Europe, America, and Asia. RIETE included consecutive patients with deep vein thrombosis (DVT) or pulmonary embolism (PE) confirmed by objective tests (compression ultrasonography or contrast venography for suspected DVT; pulmonary angiography, ventilation-perfusion lung scan, or helical computed tomography [CT] scan for suspected PE) since March 2001. Its design, rationale, and methodology have been reported elsewhere. ${ }^{13}$ Exclusion criteria were a current enrollment in a therapeutic clinical trial with a blinded therapy. Informed consent was obtained from all participants in accordance with local ethics committee requirements.

All patients with biopsy-proven active cancer in the lung presenting with acute symptomatic, objectively confirmed VTE were considered for this study. Those with incidentally found VTE were excluded. Characteristics of the index VTE episode and of patients (demographics, comorbidities, additional risk factors for VTE, concomitant medications, initial and long-term therapy, and outcomes during anticoagulation) were recorded. VTE was considered to be secondary to surgery if appearing within 2 months of the procedure, and secondary to immobilization if within 2 months of confinement to bed with bathroom privileges for $\geq 4$ days. Active cancer included cancer diagnosed within the 3 months prior to the incident VTE, metastatic cancer, or cancer with current therapy (surgery, chemotherapy, radiotherapy, hormonal or support therapy).

Patients were managed according to the clinical practice of each participating hospital (i.e., there was no standardization of treatment). The type, dose, and duration of anticoagulant therapy were recorded. After VTE diagnosis, all patients were followed up in the outpatient clinic for at least 3 months. During each visit, any signs or symptoms suggesting recurrent DVT or PE or major bleeding were noted. All episodes of clinically suspected VTE recurrences were investigated by repeat compression ultrasonography, helical CT pulmonary, ventilation-perfusion lung scintigraphy, angiography, or pulmonary angiography. Recurrent VTE was defined as a DVT in a new segment, a DVT $4 \mathrm{~mm}$ larger in diameter when compared with prior venous ultrasound, a new ventilation-perfusion mismatch in a lung scan, or a new intraluminal filling defect on a CT scan. Bleeding complications were classified as "major" if they were overt and required a transfusion of two units of blood or more; or were retroperitoneal, spinal, or intracranial; or when they were fatal. This definition is similar to that from the ISTH, with the only exception that in RIETE we do not consider a decrease of $2 \mathrm{~g} / \mathrm{dL}$ of hemoglobin as a criterion. Fatal PE, in the absence of autopsy, was defined as any death appearing within 10 days after symptomatic PE diagnosis, in the absence of any alternative cause of death. Fatal bleeding was considered as any death appearing within 10 days after a major bleed, in the absence of any alternative cause of death.

Categorical variables were compared using the chi-square test (two-sided) and Fisher's exact test (two-sided). Continuous variables were compared using Student's $t$-test. Hazard ratios (HR) and corresponding 95\% confidence intervals (CIs) were calculated. Incidence rates were calculated as cumulative incidence (events/100 patient-years) and compared using the HRs. All analyses used time-to-event methods. Risks of recurrent VTE or major bleeding were assessed with proportional hazard Cox models. Time zero was the date of diagnosis of VTE and patients were censored at the time of discontinuation of anticoagulation, at the time of death, or at the last date for which outcome data were available. The 
assumption of independence of the time distribution between outcomes (VTE recurrences or major bleeding) and death may not be satisfied in survival analysis due to the competing risk of death. Therefore, the Kaplan-Meier method was not appropriate to estimate survival curves for VTE. Kaplan-Meier method and log-rank test were used to compare the function of cumulative incidence for each outcome between both groups of patients (PE patients group vs. DVT patients group). Then a competing risk analysis with the Fine and Gray method was performed. Covariates included in the adjusted model were those for which a statistically significant difference (a threshold $p$-value of 0.1 was set to assess significance of differences) was found between the different variables, and a backward selection was used for the covariate selection in the multivariable model. Statistical analyses were conducted with SPSS for Windows Release (version 20; SPSS Inc. Chicago, Illinois, United States).

\section{Results}

As of May 2017, a total of 10,962 patients with active cancer were recruited in RIETE, of whom 1,725 (16\%) had lung cancer. There were 1,250 men (72\%) and 475 women, aged $65 \pm 12$ years, and most (74\%) had metastases. Overall, 1,208 patients (70\%) presented with symptomatic PE (with or without concomitant DVT) and 517 with symptomatic DVT alone.

VTE was diagnosed during the first 90 days after cancer diagnosis in 865 patients (50\%), including 546 (32\%) in whom VTE occurred during the first 30 days ( - Table 1). Additional risk factors for VTE included recent surgery (7.5\%) or immobilization (20\%). Eighty-four of 129 patients with recent surgery (65\%) and 111 of 346 with recent immobilization (32\%) had received VTE prophylaxis. Half of the patients (51\%) were receiving chemotherapy at baseline, and 23\% were receiving corticosteroids. Among 1,208 patients presenting with PE, 1,051 (87\%) had dyspnea, 462 (38\%) chest pain, 95 (7.9\%) hemoptysis, and 94 (7.8\%) had syncope. Among 517 patients presenting with DVT, 124 (24\%) had upper extremity DVT (secondary to catheter in 51). At VTE diagnosis, 1,007 patients (58\%) had anemia, 359 (21\%) had a platelet count lower than $100,000 / \mu \mathrm{L}$, and 468 (27\%) had creatinine clearance $(\mathrm{CrCl})$ levels lower than $60 \mathrm{~mL} / \mathrm{min}$.

Most patients (90\%) were initially treated with lowmolecular-weight heparin (LMWH), independently of initial presentation as PE or DVT, but those with PE were more likely to receive unfractionated heparin (UFH) or thrombolytics than those with DVT alone (- Table 2). Then, most patients in both subgroups (65\%) continued on LMWH for long-term therapy. A small proportion of patients received Fondaparinux $(1.4 \%)$, direct oral anticoagulants $(0.5 \%)$, or a vena cava filter $(1.7 \%)$.

During the course of anticoagulation (median duration, 93 days), 166 patients developed symptomatic VTE recurrences (recurrent PE: 80, recurrent DVT: 86), 63 had major bleeding (gastrointestinal: 27, intracranial: 11), and 870 died (-Table 3). There were no differences in the rates of PE recurrences (HR: 0.76; 95\% CI: 0.48-1.20), major bleeding (HR: 0.99; 95\% CI: 0.58-1.70), or death (HR: 1.03 ; 95\% CI:
Table 1 Clinical characteristics of the patients, according to initial VTE presentation

\begin{tabular}{|c|c|c|c|}
\hline & $\begin{array}{l}\text { Pulmonary } \\
\text { embolism }\end{array}$ & $\begin{array}{l}\text { Deep vein } \\
\text { thrombosis }\end{array}$ & $\begin{array}{l}\text { Odds ratio } \\
(95 \% \mathrm{Cl})\end{array}$ \\
\hline Patients, $N$ & 1,208 & 517 & \\
\hline \multicolumn{4}{|l|}{ Clinical characteristics } \\
\hline Male gender & $873(72 \%)$ & $377(73 \%)$ & $0.97(0.77-1.22)$ \\
\hline Age (mean $y \pm S D$ ) & $65 \pm 12$ & $65 \pm 12$ & - \\
\hline $\begin{array}{l}\text { Body weight } \\
\text { (mean } \mathrm{kg} \pm \mathrm{SD} \text { ) }\end{array}$ & $72 \pm 14$ & $72 \pm 14$ & - \\
\hline \multicolumn{4}{|l|}{ Cancer characteristics } \\
\hline Metastatic & $883(73 \%)$ & $387(75 \%)$ & $0.91(0.72-1.16)$ \\
\hline \multicolumn{4}{|l|}{$\begin{array}{l}\text { Time elapsed since } \\
\text { cancer diagnosis }\end{array}$} \\
\hline$<90 \mathrm{~d}$ & $607(50 \%)$ & $258(50 \%)$ & $1.01(0.83-1.25)$ \\
\hline$<30 d$ & $399(33 \%)$ & $147(28 \%)$ & $1.24(0.99-1.56)$ \\
\hline \multicolumn{4}{|l|}{ Cancer therapy } \\
\hline Radiotherapy & $50(4.1 \%)$ & $28(5.4 \%)$ & $0.75(0.47-1.21)$ \\
\hline Chemotherapy & $468(39 \%)$ & $198(38 \%)$ & $1.02(0.82-1.26)$ \\
\hline $\begin{array}{l}\text { Radio- and } \\
\text { chemotherapy }\end{array}$ & $151(13 \%)$ & $63(12 \%)$ & $1.03(0.75-1.41)$ \\
\hline \multicolumn{4}{|l|}{ Underlying conditions } \\
\hline $\begin{array}{l}\text { Chronic lung } \\
\text { disease }\end{array}$ & $72(6.0 \%)$ & $19(3.7 \%)$ & $1.66(0.99-2.78)$ \\
\hline $\begin{array}{l}\text { Chronic heart } \\
\text { failure }\end{array}$ & $316(26 \%)$ & $99(19 \%)$ & $1.50(1.16-1.93)$ \\
\hline \multicolumn{4}{|c|}{ Additional risk factors for VTE } \\
\hline Recent surgery & $104(8.6 \%)$ & $25(4.8 \%)$ & $1.85(1.18-2.91)$ \\
\hline $\begin{array}{l}\text { VTE prophylaxis } \\
\text { (yes) }\end{array}$ & $67(64 \%)$ & $17(68 \%)$ & $0.85(0.32-2.16)$ \\
\hline Immobility $\geq 4 \mathrm{~d}$ & $243(20 \%)$ & $103(20 \%)$ & $1.01(0.78-1.31)$ \\
\hline $\begin{array}{l}\text { VTE prophylaxis } \\
\text { (yes) }\end{array}$ & $78(32 \%)$ & $33(32 \%)$ & $1.00(0.61-1.66)$ \\
\hline Use of estrogens & $14(1.2 \%)$ & $4(0.8 \%)$ & $1.50(0.49-4.59)$ \\
\hline None of the above & $871(72 \%)$ & $391(76 \%)$ & $0.83(0.66-1.06)$ \\
\hline Prior VTE & $123(10 \%)$ & $66(13 \%)$ & $0.78(0.56-1.07)$ \\
\hline \multicolumn{4}{|l|}{ Concomitant therapies } \\
\hline Antiplatelets & $159(13 \%)$ & $76(15 \%)$ & $0.88(0.66-1.18)$ \\
\hline Corticosteroids & $282(23 \%)$ & $112(22 \%)$ & $1.10(0.86-1.41)$ \\
\hline \multicolumn{4}{|l|}{ Blood tests } \\
\hline Anemia & $678(56 \%)$ & $329(64 \%)$ & $0.73(0.59-0.90)$ \\
\hline $\begin{array}{l}\text { Platelet count } \\
<100,000 / \mu \mathrm{L}\end{array}$ & $245(20 \%)$ & $114(22 \%)$ & $0.90(0.70-1.15)$ \\
\hline $\begin{array}{l}\text { Platelet count } \\
>450,000 / \mu \mathrm{L}\end{array}$ & $90(7.5 \%)$ & $25(4.8 \%)$ & $1.58(0.99-2.49)$ \\
\hline $\begin{array}{l}\mathrm{CrCl} \text { levels } \\
<60 \mathrm{~mL} / \mathrm{min}\end{array}$ & $322(27 \%)$ & $146(28 \%)$ & $0.92(0.73-1.16)$ \\
\hline
\end{tabular}

Abbreviations: $\mathrm{Cl}$, confidence intervals; $\mathrm{CrCl}$, creatinine clearance; SD, standard deviation; VTE, venous thromboembolism.

0.89-1.18) between patients with PE and DVT, but patients initially presenting with PE had a lower rate of DVT recurrences (HR: 0.62; 95\% CI: 0.40-0.96) than those with DVT. Interestingly, the rate of VTE recurrences was twofold higher than the rate of major bleeding during the first 30 days of anticoagulant therapy (61 vs. 33 events) and over fourfold 
Table 2 Treatment strategies, according to initial VTE presentation

\begin{tabular}{|c|c|c|c|}
\hline & $\begin{array}{l}\text { Pulmonary } \\
\text { embolism }\end{array}$ & $\begin{array}{l}\text { Deep vein } \\
\text { thrombosis }\end{array}$ & $\begin{array}{l}\text { Odds ratio } \\
(95 \% \mathrm{Cl})\end{array}$ \\
\hline Patients, $N$ & 1,208 & 517 & \\
\hline \multicolumn{4}{|l|}{ Duration of therapy } \\
\hline $\begin{array}{l}\text { Mean days } \\
( \pm \text { SD })\end{array}$ & $124 \pm 140$ & $149 \pm 247$ & $p=0.008$ \\
\hline $\begin{array}{l}\text { Median days } \\
\text { (interquartile } \\
\text { range) }\end{array}$ & $93(125)$ & $92(155)$ & $p=0.80$ \\
\hline $\begin{array}{l}\text { Duration } \\
>6 \text { months }\end{array}$ & 307 (26\%) & $106(21 \%)$ & $1.32(1.03-1.69)$ \\
\hline \multicolumn{4}{|l|}{ Initial therapy } \\
\hline LMWH & $1,067(88 \%)$ & 478 (93\%) & $0.62(0.43-0.89)$ \\
\hline $\begin{array}{l}\text { Mean LMWH } \\
\text { dose }(I U / \mathrm{kg} / \mathrm{d})\end{array}$ & $177 \pm 42$ & $175 \pm 48$ & $p=0.39$ \\
\hline $\begin{array}{l}\text { Unfractionated } \\
\text { heparin }\end{array}$ & $93(7.7 \%)$ & $19(3.7 \%)$ & $2.19(1.32-3.62)$ \\
\hline Fondaparinux & $18(1.5 \%)$ & $6(1,2 \%)$ & $1.29(0.51-3.26)$ \\
\hline Thrombolytics & $16(1.3 \%)$ & 0 & - \\
\hline DOACs & 0 & $3(0.2 \%)$ & - \\
\hline $\begin{array}{l}\text { Inferior vena } \\
\text { cava filter }\end{array}$ & $23(1.9 \%)$ & $7(1.4 \%)$ & $1.41(0.60-3.32)$ \\
\hline \multicolumn{4}{|l|}{ Long-term therapy } \\
\hline LMWH & $764(63 \%)$ & $349(68 \%)$ & $0.83(0.67-1.03)$ \\
\hline $\begin{array}{l}\text { Mean LMWH } \\
\text { dose (IU/kg/day) }\end{array}$ & $156 \pm 42$ & $153 \pm 45$ & $p=0.28$ \\
\hline $\begin{array}{l}\text { Vitamin K } \\
\text { antagonists }\end{array}$ & 159 (13\%) & $83(16 \%)$ & $0.79(0.59-1.06)$ \\
\hline Fondaparinux & $13(1.1 \%)$ & $8(1.5 \%)$ & $0.69(0.29-1.68)$ \\
\hline DOACs & $7(0.6 \%)$ & $1(0.2 \%)$ & $3.01(0.37-24.5)$ \\
\hline
\end{tabular}

Abbreviations: $\mathrm{Cl}$, confidence intervals; DOACs, direct oral anticoagulants; IU, international units; LMWH, low-molecular-weight heparin; SD, standard deviation.

higher (105 vs. 30 events) beyond the first month ( - Table 3 and - Fig. 1).

Of 870 patients who died during anticoagulation, 57 (6.6\%) died of PE (9 during the first 24 hours) and 15 (1.7\%) died of bleeding. Most fatal PEs (48 of $57,84 \%$ ) and most fatal bleeds (10 of $15,67 \%$ ) occurred within the first 30 days of therapy (-Fig. 2). The case-fatality rate of PE recurrences ( 18 of 80 events were fatal: $22.5 \%$; $95 \% \mathrm{CI}$ : $14.4-$ 32.6) and major bleeding (15 of 63 bleeds: $23.8 \%$; $95 \% \mathrm{CI}$ : 14.5-35.5) was similar. Compared with patients who did not die of PE or bleeding, those with fatal PE were more likely to initially present with $\mathrm{PE}$, to be immobilized recently (only $28 \%$ had received VTE prophylaxis), to be using corticosteroids, to have raised platelet count at baseline, or to be initially treated with UFH ( - Table 4). Of 72 patients dying of PE or bleeding, 15 (21\%) had no metastases, 26 (36\%) were diagnosed with cancer less than 3 months before, and 29 (40\%) developed VTE shortly after surgery or immobility.

On multivariable analyses, patients with $\mathrm{CrCl}$ levels less than $60 \mathrm{~mL} / \mathrm{min}$ were at lower risk for PE recurrences (HR: 0.52; 95\% CI: 0.28-0.96) and those with recent major bleeding at baseline were at increased risk for major bleeding during anticoagulation (HR: 4.01; 95\% CI: 1.36-11.9). We failed to find other independent predictors for these outcomes.

\section{Discussion}

Our data, obtained from a large series of patients with lung cancer and symptomatic VTE, reveal that 72 of 870 patients (8.3\%) dying during the course of anticoagulant therapy died of PE or bleeding. Of these, one in every five patients (21\%) had no metastases. Thus, the clinical relevance of VTE in lung cancer patients should not be underestimated. Interestingly, VTE often appeared early in the course of lung cancer: half (50\%) of the patients had been diagnosed with cancer less than 3 months prior to VTE, 32\% less than 30 days before. One in every three patients (32\%) had not received chemo- or radiotherapy yet. Thus, active surveillance on early signs and symptoms of VTE appearing in patients with recently diagnosed lung cancer might likely help detect VTE earlier, and treat it more efficiently. Previous studies also reported that the risk of VTE is highest in the first few months after the diagnosis of several malignancies, including the lung. ${ }^{2,14-16}$

One in every nine patients (16\%) with fatal PE in our cohort died within the first 24 hours, with few time for anticoagulant therapy to be effective. Therefore, accurate identification of at-risk patients would likely help prescribe adequate preventive measures and to detect VTE earlier. In our cohort, one in every four patients (28\%) dying of PE or bleeding developed VTE shortly after surgery or immobilization, but only 65 and 32\%, respectively, did receive prophylaxis. A wider prescription of effective and safe prophylaxis of VTE (particularly during periods of immobility) might have reduced the amount of patients developing VTE, and thus the amount of patients dying of PE or bleeding.

Over half of the patients (58\%) in our cohort had anemia, one in every four had renal insufficiency $(27 \%)$ or were using corticosteroids (23\%), and one in every five (21\%) had thrombocytopenia. Not unexpectedly, the rate of major bleeding events appearing during the course of anticoagulant therapy was high (10 major bleeds per 100 patient-years). However, the rate of VTE recurrences was over twofold higher than the rate of major bleeding, and the rate of fatal $P E$ also exceeded the rate of fatal bleeding ( 57 and 15 deaths, respectively). Since up to half of the VTE recurrences and major bleeds did appear during the first 30 days of therapy, this is the time when patients should be more closely monitored. Unfortunately, however, we failed to find independent predictors for VTE recurrences or major bleeding, other than renal function and recent major bleeding.

As in previous cohort studies and randomized clinical trials, the highest rates of VTE recurrences and major bleeding in our cohort occurred during the first weeks of therapy. ${ }^{2,17-23}$ In a recent study, we reported that the rate of VTE recurrences during anticoagulation was similar to the rate of major bleeding in patients with breast or colorectal cancer, much higher in those with lung cancer, and lower in patients with prostatic cancer. ${ }^{24}$ These findings may be explained by differences in the characteristics of the different tumors or 
Table 3 Clinical outcomes during the course of anticoagulant therapy, according to initial VTE presentation

\begin{tabular}{|c|c|c|c|c|c|}
\hline & \multicolumn{2}{|c|}{ Pulmonary embolism } & \multicolumn{2}{|c|}{ Deep vein thrombosis } & \multirow{2}{*}{$\begin{array}{l}\text { Hazard ratio } \\
(95 \% \mathrm{Cl})\end{array}$} \\
\hline & $N$ & $\begin{array}{l}\text { Events per } 100 \\
\text { patient-years }\end{array}$ & $N$ & $\begin{array}{l}\text { Events per } 100 \\
\text { patient-years }\end{array}$ & \\
\hline Patients, $N$ & \multicolumn{2}{|c|}{1,208} & \multicolumn{2}{|l|}{517} & \\
\hline Patient-years of therapy & \multicolumn{2}{|c|}{492.6} & \multicolumn{2}{|c|}{175.2} & \\
\hline Recurrent PE & 52 & $10.6(7.88-13.8)$ & 28 & $16.0(10.6-23.1)$ & $0.76(0.48-1.20)$ \\
\hline Recurrent DVT & 52 & $10.6(7.88-13.8)$ & 34 & $19.4(13.4-27.1)$ & $0.62(0.40-0.96)$ \\
\hline Recurrent VTE & 104 & $21.1(17.3-2.56)$ & 62 & $35.4(27.1-45.4)$ & $0.68(0.50-0.94)$ \\
\hline Major bleeding & 44 & $8.93(6.49-12.0)$ & 19 & $10.8(6.53-16.9)$ & $0.99(0.58-1.70)$ \\
\hline \multicolumn{6}{|l|}{ Site of major bleeding } \\
\hline Gastrointestinal & 16 & $3.25(1.86-5.28)$ & 11 & $6.28(3.13-11.2)$ & $0.63(0.29-1.36)$ \\
\hline Cerebral & 7 & $1.42(0.57-2.93)$ & 4 & $2.28(0.61-5.85)$ & $0.73(0.21-2.51)$ \\
\hline Death & 622 & $126(117-137)$ & 248 & $142(125-160)$ & $1.03(0.89-1.19)$ \\
\hline \multicolumn{6}{|l|}{ Causes of death } \\
\hline Initial PE & 39 & $7.92(5.63-10.8)$ & - & - & - \\
\hline Recurrent PE & 13 & $2.64(1.40-4.51)$ & 5 & $2.85(0.92-6.66)$ & $1.15(0.41-3.22)$ \\
\hline Bleeding & 9 & $1.83(0.83-3.47)$ & 6 & $3.42(1.25-7.46)$ & $0.66(0.23-1.85)$ \\
\hline Respiratory insufficiency & 49 & $9.95(7.36-13.1)$ & 12 & $6.85(3.54-12.0)$ & $1.77(0.94-3.33)$ \\
\hline Sudden, unexpected & 4 & $0.81(0.22-2.08)$ & 2 & $1.14(0.13-4.12)$ & $0.89(0.16-4.85)$ \\
\hline \multicolumn{6}{|l|}{ 30-d outcomes } \\
\hline Recurrent PE & \multicolumn{2}{|c|}{$25(2.1 \%)$} & \multicolumn{2}{|c|}{$12(2.3 \%)$} & $0.92(0.46-1.83)$ \\
\hline Recurrent DVT & \multicolumn{2}{|c|}{$16(1.3 \%)$} & \multicolumn{2}{|c|}{$13(2.5 \%)$} & $0.54(0.26-1.13)$ \\
\hline Recurrent VTE & \multicolumn{2}{|c|}{$41(3.4 \%)$} & \multicolumn{2}{|c|}{$25(4.8 \%)$} & $0.72(0.44-1.19)$ \\
\hline Major bleeding & \multicolumn{2}{|c|}{$24(2.0 \%)$} & \multicolumn{2}{|c|}{$12(2.3 \%)$} & $0.88(0.44-1.77)$ \\
\hline Death & \multicolumn{2}{|c|}{$269(22 \%)$} & \multicolumn{2}{|c|}{$92(18 \%)$} & $1.29(1.02-1.63)$ \\
\hline Fatal PE & \multicolumn{2}{|c|}{$8(0.7 \%)$} & \multicolumn{2}{|c|}{$3(0.6 \%)$} & $1.18(0.31-4.44)$ \\
\hline Fatal bleeding & \multicolumn{2}{|c|}{$6(0.5 \%)$} & \multicolumn{2}{|c|}{$5(1.0 \%)$} & $0.53(0.16-1.74)$ \\
\hline
\end{tabular}

Abbreviations: $\mathrm{Cl}$, confidence intervals; DVT, deep vein thrombosis; PE, pulmonary embolism; VTE, venous thromboembolism.

their therapies, and suggest that different clinical profiles with regard to VTE-related outcomes are observed according to the primary cancer site. These data support the development of specific research addressed to evaluate cancerspecific anticoagulant strategies with regard to intensity and duration that would help tailoring VTE management.

To our knowledge, ours is the largest cohort of patients with lung cancer and VTE. Our study, however, has several limitations. First, as an observational registry, patients in RIETE were not treated with a standardized regimen; treatment varied with local practices and is likely to have been influenced by a physician's assessment of a patient's risk of bleeding or recurrent events. Factors including type, extent and rate of progression of cancer, concomitant chemotherapy, affordability of treatment, and patient preferences would have all influenced the outcomes. Second, RIETE does not have a central adjudication committee, and the causes of death relied on the reports by attending doctors. Certainly, some doctors may have underestimated the relative frequency of fatal PEs or fatal bleeding, since we looked at symptomatic VTE recurrences and bleeding events, but there could have been several patients dying at home who were considered to die of "cancer," or of unknown reasons. On the contrary, the risk to have overestimated these risks seems lower given the strict definition of fatal PE and fatal bleeding in RIETE. Finally, the median duration of anticoagulation was only 3 months. This was largely due to the high mortality rate in our cohort, since $50 \%$ of patients died during follow-up.

In conclusion, one in every five patients dying of PE or bleeding had no metastases and one in every three had developed the VTE shortly after surgery or immobility. Since half of the patients had been diagnosed with cancer less than 3 months prior to VTE, we suggest that active surveillance on early signs and/or symptoms of VTE in patients with recently diagnosed lung cancer and prescription of VTE prophylaxis in patients undergoing surgery or during periods of immobilization might likely help prevent VTE better, detect it earlier, and treat it more efficiently. 


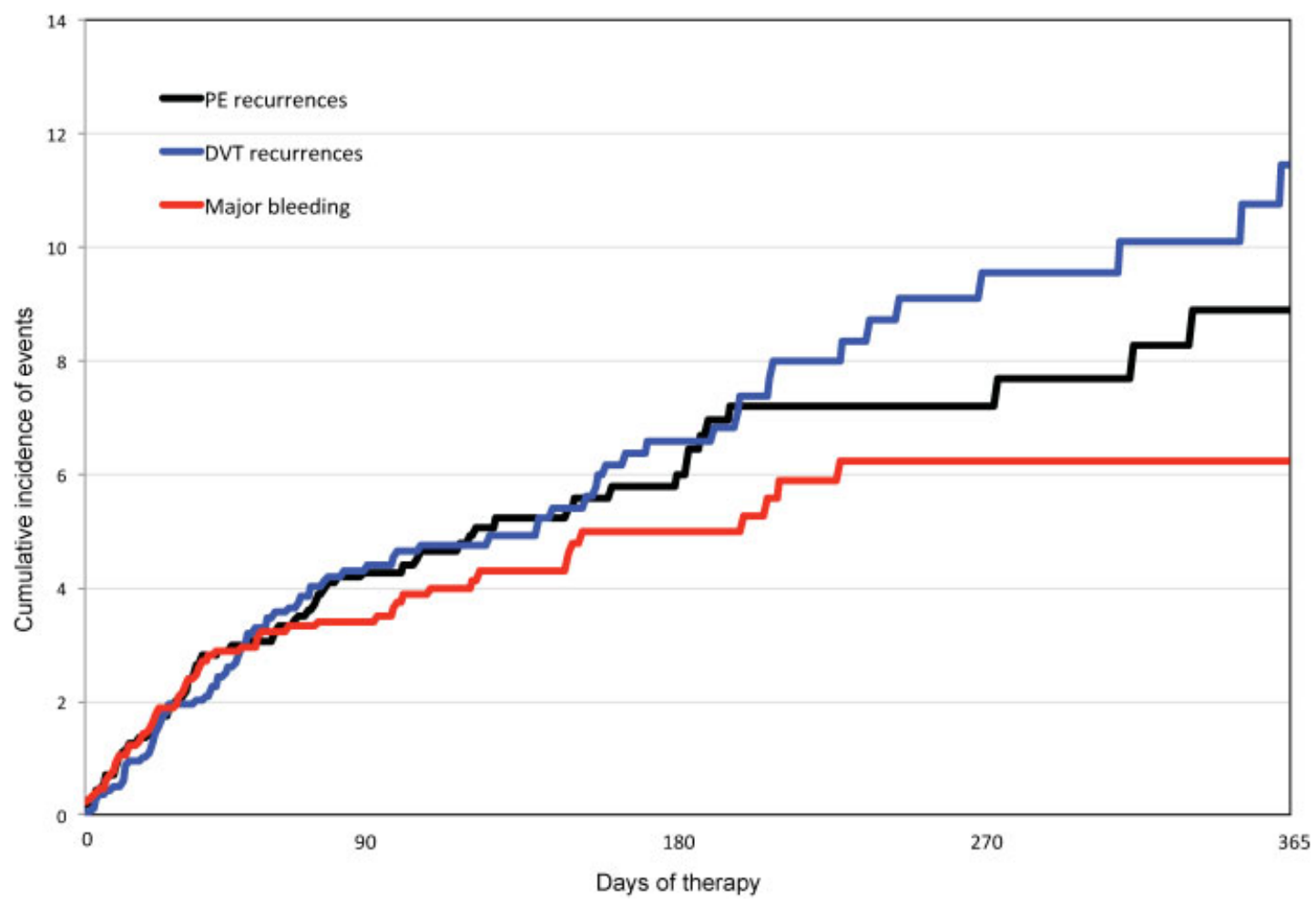

Fig. 1 Cumulative rate of PE recurrences, DVT recurrences, and major bleeding during anticoagulation. DVT, deep vein thrombosis; PE, pulmonary embolism.

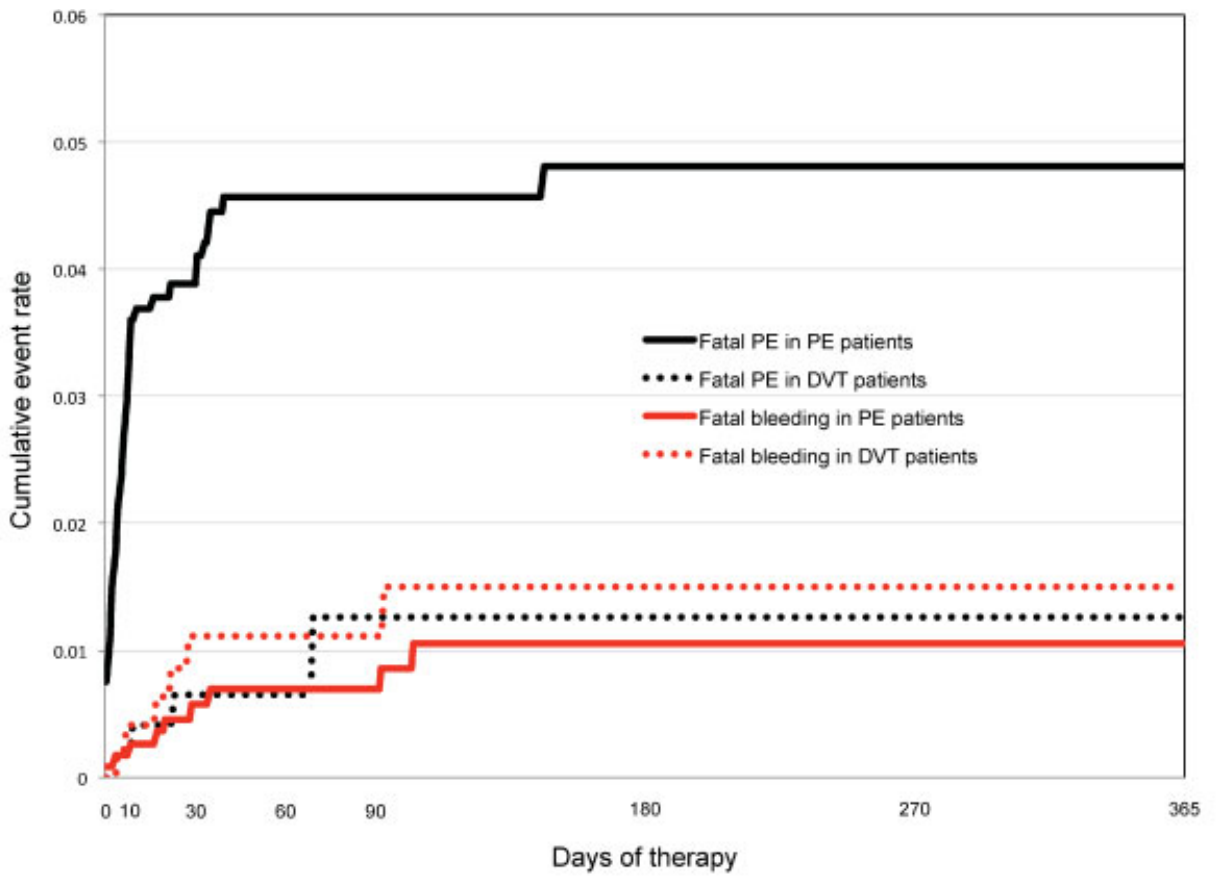

\begin{tabular}{|l|l|l|l|l|l|l|l|}
\hline Days & 10 & 30 & 60 & 90 & 180 & 365 \\
\hline \multirow{3}{*}{ PE patients } & At risk & 1,079 & 887 & 731 & 624 & 316 & 104 \\
\cline { 2 - 8 } & Fatal PE & $42(3.5 \%)$ & $45(3.7 \%)$ & $51(4.2 \%)$ & $51(4.2 \%)$ & $52(4.3 \%)$ & $52(4.3 \%)$ \\
\cline { 2 - 8 } & Fatal bleeding & $3(0.2 \%)$ & $5(0.4 \%)$ & $7(0.6 \%)$ & $7(0.6 \%)$ & $9(0.7 \%)$ & $9(0.7 \%)$ \\
\hline \multirow{3}{*}{ DVT patients } & At risk & 475 & 403 & 336 & 284 & 109 & 27 \\
\cline { 2 - 8 } & Fatal PE & $1(0.2 \%)$ & $3(0.6 \%)$ & $3(0.6 \%)$ & $5(1.0 \%)$ & $5(1.0 \%)$ & $5(1.0 \%)$ \\
\cline { 2 - 8 } & Fatal bleeding & $2(0.4 \%)$ & $5(1.0 \%)$ & $5(1.0 \%)$ & $5(1.0 \%)$ & $6(1.2 \%)$ & $6(1.2 \%)$ \\
\hline
\end{tabular}

Fig. 2 Cumulative rates of fatal PE and fatal bleeding, according to initial VTE presentation. DVT, deep vein thrombosis; PE, pulmonary embolism. 
Table 4 Clinical characteristics of patients who died of PE or bleeding

\begin{tabular}{|c|c|c|c|}
\hline & Fatal PE & $\begin{array}{l}\text { Fatal } \\
\text { bleeding }\end{array}$ & Neither \\
\hline Patients, $N$ & 57 & 15 & 1,653 \\
\hline \multicolumn{4}{|l|}{ Clinical characteristics } \\
\hline Male gender & $38(67 \%)$ & $12(80 \%)$ & $1,200(73 \%)$ \\
\hline Age $<50$ y & $3(5.3 \%)$ & $2(13 \%)$ & $168(10 \%)$ \\
\hline \multicolumn{4}{|l|}{ Initial VTE presentation } \\
\hline Pulmonary embolism & $52(91 \%)^{\ddagger}$ & $9(60 \%)$ & $1,147(69 \%)$ \\
\hline \multicolumn{4}{|l|}{ Cancer characteristics } \\
\hline Metastases & $47(83 \%)$ & $10(67 \%)$ & $1,213(73 \%)$ \\
\hline \multicolumn{4}{|l|}{ Time since cancer diagnosis } \\
\hline$<90 \mathrm{~d}$ & $21(37 \%)$ & $5(33 \%)$ & $839(51 \%)$ \\
\hline$<30 \mathrm{~d}$ & $8(14 \%)$ & $1(6.7 \%)^{*}$ & $537(33 \%)$ \\
\hline \multicolumn{4}{|l|}{ Cancer therapy } \\
\hline Radiotherapy & $2(3.5 \%)$ & $1(6.7 \%)$ & $75(4.5 \%)$ \\
\hline Chemotherapy & $28(49 \%)$ & $7(47 \%)$ & $631(38 \%)$ \\
\hline Radio- and chemotherapy & $7(12 \%)$ & $3(20 \%)$ & 204 (12\%) \\
\hline \multicolumn{4}{|l|}{ Underlying conditions } \\
\hline Chronic lung disease & $19(33 \%)$ & $4(27 \%)$ & $392(24 \%)$ \\
\hline Chronic heart failure & $6(11 \%)$ & $1(6.7 \%)$ & $84(5.1 \%)$ \\
\hline \multicolumn{4}{|l|}{ Additional VTE risk factors } \\
\hline Postoperative & $2(3.5 \%)$ & 0 & $127(7.7 \%)$ \\
\hline Immobility $\geq 4 \mathrm{~d}$ & $23(40 \%)^{\ddagger}$ & $4(27 \%)$ & $319(19 \%)$ \\
\hline Use of estrogens & $1(18 \%)$ & $1(6.7 \%)^{*}$ & $16(1.0 \%)$ \\
\hline None of the above & $33(58 \%)^{\dagger}$ & $10(67 \%)$ & $1,219(74 \%)$ \\
\hline Prior VTE & $5(8.8 \%)$ & $3(20 \%)$ & $181(11 \%)$ \\
\hline \multicolumn{4}{|l|}{ Concomitant therapies } \\
\hline Antiplatelets & $3(5.3 \%)$ & $2(13 \%)$ & $230(14 \%)$ \\
\hline Corticosteroids & $21(37 \%)^{*}$ & $5(33 \%)$ & $368(22 \%)$ \\
\hline \multicolumn{4}{|l|}{ Blood tests } \\
\hline Anemia & $33(58 \%)$ & $11(73 \%)$ & $963(58 \%)$ \\
\hline Platelet count $<100,000 / \mu \mathrm{L}$ & $3(5.3 \%)$ & $3(20 \%)$ & $126(7.6 \%)$ \\
\hline Platelet count $>450,000 / \mu \mathrm{L}$ & $10(18 \%)^{\ddagger}$ & $2(13 \%)$ & $103(6.2 \%)$ \\
\hline $\mathrm{CrCl}$ levels $<60 \mathrm{~mL} / \mathrm{min}$ & $18(32 \%)$ & $5(33 \%)$ & $445(27 \%)$ \\
\hline \multicolumn{4}{|l|}{ Initial therapy } \\
\hline LMWH & $46(81 \%)^{*}$ & $14(93 \%)$ & $1,485(90 \%)$ \\
\hline LMWH dose $<175 \mathrm{IU} / \mathrm{kg} / \mathrm{d}$ & $13(23 \%)^{*}$ & $4(27 \%)$ & $589(36 \%)$ \\
\hline Unfractionated heparin & $9(16 \%)^{\dagger}$ & $1(6.7 \%)$ & $102(6.2 \%)$ \\
\hline Inferior vena cava filter & $1(1.8 \%)^{\ddagger}$ & $1(6.7 \%)$ & $28(1.7 \%)$ \\
\hline
\end{tabular}

Abbreviations: $\mathrm{CrCl}$, creatinine clearance; IU, international units; $\mathrm{LMWH}$, low-molecular-weight heparin; PE, pulmonary embolism; VTE, venous thromboembolism.

Notes: Patients with fatal PE or fatal bleeding were compared with patients with neither: ${ }^{*} p<0.05 ;{ }^{\dagger} p<0.01 ;{ }^{\ddagger} p<0.001$.

\section{Conflict of Interest}

None declared.

\section{Acknowledgments}

We express our gratitude to Sanofi Spain for supporting this Registry with an unrestricted educational grant. We also express our gratitude to Bayer Pharma AG for supporting this Registry. Bayer Pharma AG's support was limited to the part of RIETE outside Spain, which accounts for a $24.8 \%$ of the total patients included in the RIETE Registry. We also thank the RIETE Registry Coordinating Center, S\&H Medical Science Service, for their quality control data, logistic, and administrative support.

\section{References}

1 Siegel R, Naishadham D, Jemal A. Cancer statistics, 2012. CA Cancer J Clin 2012;62(01):10-29

2 Chew HK, Davies AM, Wun T, Harvey D, Zhou H, White RH. The incidence of venous thromboembolism among patients with primary lung cancer. J Thromb Haemost 2008;6(04):601-608

3 Paneesha S, McManus A, Arya R, et al; VERITY Investigators. Frequency, demographics and risk (according to tumour type or site) of cancer-associated thrombosis among patients seen at outpatient DVT clinics. Thromb Haemost 2010;103(02):338-343

4 Horsted F, West J, Grainge MJ. Risk of venous thromboembolism in patients with cancer: a systematic review and meta-analysis. PLoS Med 2012;9(07):e1001275

5 Riedl J, Posch F, Königsbrügge O, et al. Red cell distribution width and other red blood cell parameters in patients with cancer: association with risk of venous thromboembolism and mortality. PLoS One 2014;9(10):e111440

6 Zhang Y, Yang Y, Chen W, et al; China Venous Thromboembolism (VTE) Study Group. Prevalence and associations of VTE in patients with newly diagnosed lung cancer. Chest 2014;146(03):650-658

7 Connolly GC, Menapace L, Safadjou S, Francis CW, Khorana AA. Prevalence and clinical significance of incidental and clinically suspected venous thromboembolism in lung cancer patients. Clin Lung Cancer 2013;14(06):713-718

8 Monreal M, Kakkar AK, Caprini JA, et al; RIETE Investigators. The outcome after treatment of venous thromboembolism is different in surgical and acutely ill medical patients. Findings from the RIETE registry. J Thromb Haemost 2004;2(11):1892-1898

9 Laporte S, Mismetti P, Décousus H, et al; RIETE Investigators. Clinical predictors for fatal pulmonary embolism in 15,520 patients with venous thromboembolism: findings from the Registro Informatizado de la Enfermedad TromboEmbolica venosa (RIETE) Registry. Circulation 2008;117(13):1711-1716

10 Muñoz-Torrero JF, Bounameaux H, Pedrajas JM, et al; Registro Informatizado de la Enfermedad TromboEmbólica (RIETE) Investigators. Effects of age on the risk of dying from pulmonary embolism or bleeding during treatment of deep vein thrombosis. J Vasc Surg 2011;54(6, Suppl):26S-32S

11 Trujillo-Santos J, Schellong S, Falga C, et al; RIETE Investigators. Low-molecular-weight or unfractionated heparin in venous thromboembolism: the influence of renal function. Am J Med 2013;126(05):425-434

12 Farge D, Trujillo-Santos J, Debourdeau P, et al; RIETE Investigators. Fatal events in cancer patients receiving anticoagulant therapy for venous thromboembolism. Medicine (Baltimore) 2015;94(32):e1235

13 Bikdeli B, Jimenez D, Hawkins $\mathrm{M}$, et al; RIETE Investigators. Rationale, Design and methodology of the computerized registry of patients with venous thromboembolism (RIETE). Thromb Haemost 2018;118(01):214-224

14 Blom JW, Doggen CJ, Osanto S, Rosendaal FR. Malignancies, prothrombotic mutations, and the risk of venous thrombosis. JAMA 2005;293(06):715-722

15 Blom JW, Osanto S, Rosendaal FR. The risk of a venous thrombotic event in lung cancer patients: higher risk for adenocarcinoma than squamous cell carcinoma. J Thromb Haemost 2004;2(10): $1760-1765$ 
16 Kourelis TV, Wysokinska EM, Wang Y, Yang P, Mansfield AS, Tafur AJ. Early venous thromboembolic events are associated with worse prognosis in patients with lung cancer. Lung Cancer 2014;86(03):358-362

17 Chee CE, Ashrani AA, Marks RS, et al. Predictors of venous thromboembolism recurrence and bleeding among active cancer patients: a population-based cohort study. Blood 2014;123(25): 3972-3978

18 Francis CW, Kessler CM, Goldhaber SZ, et al. Treatment of venous thromboembolism in cancer patients with dalteparin for up to 12 months: the DALTECAN Study. J Thromb Haemost 2015;13(06): 1028-1035

19 Meyer G, Marjanovic Z, Valcke J, et al. Comparison of lowmolecular-weight heparin and warfarin for the secondary prevention of venous thromboembolism in patients with cancer: a randomized controlled study. Arch Intern Med 2002;162(15): 1729-1735

20 Lee AY, Levine MN, Baker RI, et al; Randomized Comparison of Low-Molecular-Weight Heparin versus Oral Anticoagulant Ther- apy for the Prevention of Recurrent Venous Thromboembolism in Patients with Cancer (CLOT) Investigators. Low-molecular-weight heparin versus a coumarin for the prevention of recurrent venous thromboembolism in patients with cancer. N Engl J Med 2003;349 (02):146-153

21 Hull RD, Pineo GF, Brant RF, et al; LITE Trial Investigators. Longterm low-molecular-weight heparin versus usual care in proximal-vein thrombosis patients with cancer. Am J Med 2006;119 (12):1062-1072

22 Lee AYY, Kamphuisen PW, Meyer G, et al; CATCH Investigators. Tinzaparin vs warfarin for treatment of acute venous thromboembolism in patients with active cancer: a randomized clinical trial. JAMA 2015;314(07):677-686

23 van Es N, Louzada M, Carrier M, et al. Predicting the risk of recurrent venous thromboembolism in patients with cancer: a prospective cohort study. Thromb Res 2018;163:41-46

24 Mahé I, Chidiac J, Bertoletti L, et al; RIETE Investigators. The clinical course of venous thromboembolism may differ according to cancer site. Am J Med 2017;130(03):337-347

\section{Appendix A}

Coordinator of the RIETE Registry: Manuel Monreal. RIETE Steering Committee Members: Hervé Decousus, Paolo Prandoni, Benjamin Brenner.

RIETE National Coordinators: Raquel Barba (Spain); Pierpaolo Di Micco (Italy); Laurent Bertoletti (France); Inna Tzoran (Israel); Abilio Reis (Portugal); Marijan Bosevski (R. Macedonia); Henri Bounameaux (Switzerland); Radovan Malý (Czech Republic); Philip Wells (Canada); Peter Verhamme (Belgium).

RIETE Registry Coordinating Center: S\&H Medical Science Service.

Members of the RIETE Group: SPAIN: Aibar MA, Aibar J, Alfonso M, Amado C, Aranda C, Arcelus JI, Arenas A, Ballaz A, Barba R, Barrón M, Barrón-Andrés B, Bascuñana J, Blanco-Molina A, Bolado C, Camon AM, Carrasco C, Castejón-Pina N, Chasco L, Cruz AJ, de Ancos C, del Pozo R, del Toro J, Díaz-Pedroche MC, Díaz-Peromingo JA, Falgá C, Farfán AI, Fernández-Capitán C, Fidalgo MA, Font C, Font L, Furest I, García MA, García-Bragado F, García-Morillo M, Gavín O, Gil A, Gómez V, Gómez-Cuervo C, González-Martínez J, Grau E, Guijarro R, Guirado L, Gutiérrez J, Hernández-Blasco L, Jara-Palomares L, Jaras MJ, Jiménez D, Jou I, Joya MD, Lima J, Lobo JL, López-Jiménez L, López-Miguel P, LópezNuñez JJ, López-Reyes R, López-Sáez JB, Lorente MA, Lorenzo A,
Loring M, Loscos S, Lumbierres M, Maestre A, Marchena PJ, Martínez-Baquerizo C, Martín-Asenjo M, Martín-Fernández M, Martín-Guerra JM, Monreal M, Morales MV, Nieto JA, Núñez MJ, Olivares MC, Otalora S, Otero R, Pedrajas JM, Pellejero G, PérezDuctor C, Peris ML, Pesce ML, Porras JA, Riesco D, Rivas A, Rodríguez-Dávila MA, Rodríguez-Galán I, Rodríguez-Hernández A, Rosa V, Rubio CM, Ruiz-Artacho P, Ruiz-Ruiz J, Sahuquillo JC, Sala-Sainz MC, Sampériz A, Sánchez-Muñoz-Torrero JF, SanchoT, Sanoja ID, Soler S, Soto MJ, Suriñach JM, Torres MI, Trujillo-Santos J, Uresandi F, Usandizaga E, Valle R, Vela J, Vilar C, Villalobos A; ARGENTINA: Gutiérrez P, Vázquez FJ, Vilaseca A; BELGIUM: Vanassche T, Vandenbriele C, Verhamme P; BRAZIL: Yoo HHB; CZECH REPUBLIC: Hirmerova J, Malý R; ECUADOR: Salgado E; FRANCE: Benzidia I, Bertoletti L, Bura-Riviere A, Farge-Bancel D, Hij A, Merah A, Mahé I, Moustafa F; ISRAEL: Braester A, Brenner B, Ellis M, Tzoran I; ITALY: Bilora F, Bortoluzzi C, Brandolin B, Bucherini E, Ciammaichella M, Dentali F, Di Micco P, Di Pangrazio M, Grandone E, Imbalzano E, Maida R, Mastroiacovo D, Ngoc V, Pace F, Parisi R, Pesavento R, Prandoni P, Quintavalla R, Rocci A, Siniscalchi C, Sotgiu P, Tiraferri E, Tonello D, Tufano A, Ventresca A, Visonà A; LATVIA: Kalejs RV, Skride A, Vitola B; REPUBLIC OF MACEDONIA: Bosevski M, Zdraveska M; SWITZERLAND: Bounameaux H, Fresa M, Mazzolai L, Ney B, USA: Caprini J; VIETNAM: Bui HM. 